\title{
An Investigation into Gaps in the Flow of Communication at Institutional Level: Case of Universities in Lesotho
}

\author{
Mukurunge ${ }^{1}$, Takura Bhila² \\ Academic Senior Lecturer \\ ${ }^{1}$ Communication Media, ${ }^{2}$ Information and Communication Technology, \\ Limkokwing University of Creative Technology, Maseru, Lesotho
}

\begin{abstract}
This study investigated the communication challenges between staff members and management within universities in Lesotho. These communication flow gaps are mainly caused by top to bottom mode of communication with management concentrating on channeling information down to subordinates leaving little room for subordinates to express themselves freely by initiating communication with management. This mode of communication has the negative effect of demoralizing staff causing high staff turnover in the institutions of higher learning and this is detrimental to the progress of the learner. The study gathered information through questionnaires and the data was presented and analyzed quantitatively through tables and graphs. The results reflect that the top to bottom communication model predominantly used by management in Lesotho is not effective in bringing the best out of university staff.
\end{abstract}

\section{KEYWORDS: communication, top to bottom model, management}

\section{INTRODUCTION}

Effective communication within institutions of higher learning contributes to quality delivery to the learner who is supposed to be the central beneficiary of the education system in any country. Gaps in the flow of communication between management and teaching staff can result in frustration of teaching staff who might decide to transfer to other institutions and this staff turnover, in the long run, is detrimental to the student's learning process. Educator turnover impacts negatively on learners as institutional memory is lost and resources are wasted on the hiring process (Ronfeldt, Loeb and Wyckoff, 2012). Communication flow gaps between management and university teaching staff can result in low lecturer moral and a demoralized lecturer cannot perform to the best of her ability.

Proctor (2014) writes that organizations understand that effective communication at all levels of the organization improve organizational success and employee relations. However, with the case of Lesotho, effective communication's impact on lecturers' performance and job satisfaction as well as management communication methods in relation to employee attitudes and happiness has not been studied at the level of the higher education setting. This study therefore seeks to contribute literature on how management and lecturing staff relate by investigating the gaps that exist in the flow of communication within universities in Lesotho so as to improve management attitude and guarantee employee happiness which will result in job satisfaction and quality delivery by the lecturing staff.

Studies have proven that different aspects of effective organizational communication, such as high frequency, openness and accuracy, performance feedback, and adequacy of information about organizational policies and procedures are positively related to employees' feelings of happiness in the workplace and job performance (Kacmar, Witt, Zivnuska \& Gulley, 2003; Neves \& Eisenberger, 2012; O' Reilly \&Roberts, 1977; O’Reilly \&Roberts, 1979; Snyder \&Morris, 1984 in Proctor, 2014). Proctor (2014) goes on to cite Allen, 1992; Allen, 1995; Neves \& Eisenberger, 2012 saying that a strong relationship has been found between managerial communication, perceived organizational support (POS), and employee performance.

The problem with some of the universities in Lesotho is that communication is heavily tilted along the lines of top to bottom mode where the lecturing staff is predominantly communicated down to with very little room for fair and clear exchange of communication.

The study is carried out to investigate the gaps in the flow of communication between management and teaching staff in Lesotho universities that compromise the quality of service delivery to university students. The study is also carried out to establish the existing communication methods by university authorities with their lecturing staff and advise on how best to solve the problem of these communication flow gaps.

The question this study seeks to answer is what gaps exist in the communication flow between management and their lecturing staff in Lesotho universities that hinders quality service delivery to students and how can these gaps be filled.

\section{Literature review and theoretical framework Theoretical Framework}

The theory informing this study is the hypodermic needle theory as the communication model of choice by some universities in Lesotho is the top to bottom model, with authorities predominantly talking down to subordinates with very little tolerance, consideration and accommodation of subordinate initiated communication.

By communication standards, the hypodermic needle theory is an old theory emanating from a 1949 communication model by two researchers working for the Bell telephone company, Shannon and Weaver (Turnbull and Schwartz, 2000). With the model of the hypodermic needle theory, the 
source of the information being communicated primary concern is the transmission of the communication and that the information communicated to the recipient is final and the recipient is expected to comply with the message. With some authorities in universities in Lesotho, communication is done through sending emails to subordinates or through stand up briefings called stand up meetings where messages are relayed to lecturers from senior management through middle managers. Lecturers' feedback is not considered in any other way beyond obeying whatever will have been communicated. True to the chief characteristic of the hypodermic needle theory, such university authorities operate from the premise of trying to influence operations by subordinates directly and uniformly by " 'shooting' or 'injecting' them with appropriate messages designed to trigger a desired response" (Singh, nd).

\section{Literature Review}

As in all dimensions of social life, in educational organizations, good communication is crucial (Habaci, Celik, Habaci, Adiguzelli and Kurt, 2013). The word communication comes from the Latin word communist which means to share, to mix and to unite (Modrea, 2012) as cited in Pillay and Hoque, 2015). For an active, qualified, and productive education, effective communication skills are needed among school managers and teachers, both in the school environment and outside of it (Habaci et al, 2013).

Effective communication is the remedy to effective and efficient management performance of employees in an organization (Nebo, Nwankwo, Okonkwo and Ifeoma, 2015). Nebo et al (2015) also continue to write that there is need for every organization to endeavor and make effective communication an essential integral part of its management strategies and map out a strategic way of storing information; for this will also reduce loss of essential information and it will help to minimize organizational conflict, less misunderstanding and enhance information management.

The basic functions of management (Planning, Organizing, Staffing, Directing and Controlling) cannot be performed well without effective communication (Asamu, 2014). Citing Bass (1985), Asamu (2014) goes on to say that employees choose to perform tasks out of identification with the managers or with the organization roles and objectives. This relationship results in the employees' basic agreement with the norms to which they are required to perform (Asamu, 2014). Therefore, the flow of communication can create identification with workers internalizing desirable values, as regarding an organization's goals and objective (Asamu, 2014).

Odiaka, Obinne and Folarin (1999) write that some workers express their dissatisfaction with the organizational communication system and try to express own needs through deviant behaviors. Citing Schwartz (1973) Odiaka et al (19990 continue to write that for effective mobilization of workers, there is need to first influence them by giving correct and adequate information.

On some of the causes of information flow gaps in organizations, Karten (2002) cites the authors De Fleur, Kearney, and Pax describing cultural factors that affect how people relate to one another below:
1. Individualism versus collectivism: This difference concerns whether people place value on emotionally independent, social, organizational, or institutional affiliations (individualism) or on close knit, supportive, family like affiliations in which collaboration, loyalty, and respect are prized (collectivism).

2. High versus low context: High-context cultures are ones in which information is communicated in a comparatively indirect and subtle manner, with reliance on nonverbal cues. Low-context cultures are those in which information must be communicated explicitly, precisely, and accurately. An absence of adequate facts, details, and examples in a low-context culture may muddle the message being communicated.

3. High versus low power-distance: This characteristic concerns how people within a culture distribute power, rank, and status- whether equally to all members or according to birth order, occupation, and class or statusand how this influences the way people communicate with each other.

4. Masculinity versus femininity: This factor pertains to whether the culture tends to be traditionally masculineemphasizing success, ambition, and competitiveness- or traditionally feminine- emphasizing compassion, a nurturing stance, and class or social support.

\section{Methodology}

This study employed the quantitative technique and instruments for gathering and analyzing information. Questionnaires were distributed to employees from 3 different universities in Lesotho and follow up interviews were made to fill in outstanding questions. Random sampling was used to select the lecturers for interviews. Random sampling ensures that everyone in the target population has an equal chance of being selected hence eliminating sampling bias. Questionnaires for the lecturers were used to collect the data which was analyzed using SPSS. Face to face follow up interviews were made to gather detailed information from some managers in the universities.

\section{Results}

85 questionnaires were distributed to staff (management, academic and non academic) and 73 were collected back for analysis. This is an $86 \%$ response rate which is high. More of the respondents were lecturers (45.2\%) as shown in table 1 below.

\begin{tabular}{|c|c|c|}
\hline & Table 1: Sample size \\
\hline & 18 & 24.7 \\
\hline Management & 33 & 45.2 \\
\hline Academic & 22 & 30.1 \\
\hline Non-academic & 73 & \\
\hline Total & & \\
\hline
\end{tabular}

The table below shows a summary of the demographics. $56.2 \%$ of the respondents were female, $46.6 \%$ were between 31-40years, most of the respondents had a master's degree $(56.1 \%)$ and most of the respondents had 6-15years of experience $(63 \%)$. 
Table 2: Demographics

\begin{tabular}{|c|c|c|c|c|}
\hline Gender & Male & Female & & \\
\hline Response & $32(43.8 \%)$ & $41(56.2 \%)$ & & \\
\hline Age & $\mathbf{2 1 - 3 0}$ & $\mathbf{3 1 - 4 0}$ & $\mathbf{4 1 - 5 0}$ & $\mathbf{5 1 +}$ \\
\hline Response & $11(15 \%)$ & $34(46.6 \%)$ & $20(27.4 \%)$ & $8(10.9 \%)$ \\
\hline Education & PhD & MSc & BSc & Diploma \\
\hline Response & $7(9.6 \%)$ & $41(56.1 \%)$ & $18(24.7 \%)$ & $7(9.6 \%)$ \\
\hline Working Experience & $\mathbf{1 - 5 y e a r s}$ & $\mathbf{6 - 1 0}$ years & $\mathbf{1 1 - 1 5 y e a r s}$ & $\mathbf{1 5 +}$ \\
\hline Response & $32(43.8 \%)$ & $23(31.5 \%)$ & $14(31.5 \%)$ & $4(5.5 \%)$ \\
\hline
\end{tabular}

The figure below illustrates that there is more of downward communication than upward communication.

\section{Figure 1: Type of Communication}

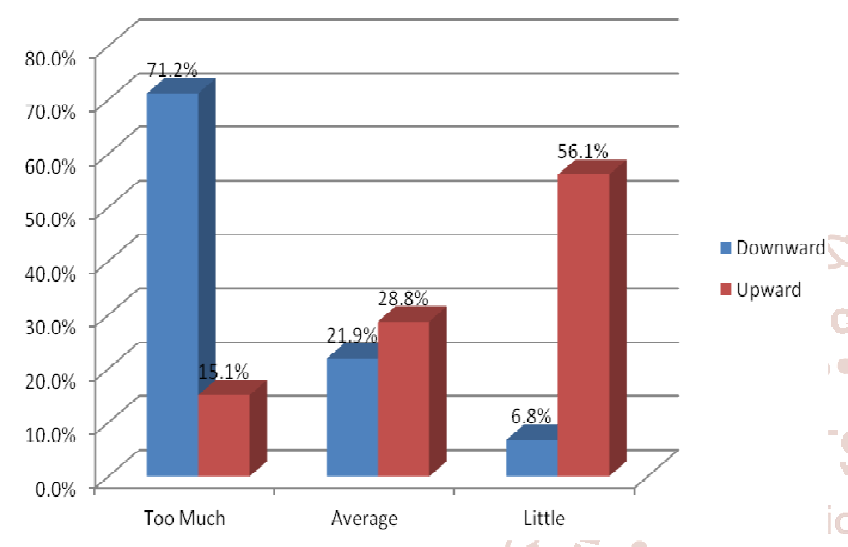

Table 3 and 4 show the gaps/problems in communication at universities in Lesotho.

Table 3: Gaps in downward communication

\begin{tabular}{|l|c|}
\hline Gaps in downward communication & Response \\
\hline Communication not timeous & $63(86.3 \%)$ \\
\hline $\begin{array}{l}\text { No feedback after participating in } \\
\text { programs/activities }\end{array}$ & $67(91.7 \%)$ \\
\hline Information overload & $54(74 \%)$ \\
\hline
\end{tabular}

Table 4: Gaps in Upward Communication

\begin{tabular}{|l|c|}
\hline \multicolumn{1}{|c|}{ Gaps in upward communication } & Response \\
\hline $\begin{array}{l}\text { No response after communicating } \\
\text { with management }\end{array}$ & $57(78.1 \%)$ \\
\hline $\begin{array}{l}\text { Communication blocked by middle } \\
\text { management }\end{array}$ & $46(63 \%)$ \\
\hline Fear of victimisation & $41(56.2 \%)$ \\
\hline Reluctance/Indifference & $33(45.2 \%)$ \\
\hline Feedback after a long time & $59(80.8 \%)$ \\
\hline Other & $21(28.9 \%)$ \\
\hline
\end{tabular}

\section{Analysis}

The study established that with top to bottom mode of communication, communication is not executed timeously as subordinates receive information at the last minute or when the activity or programme is already underway or past, as shown in table 3 with $86.3 \%$ respondents affirming this. Respondents, as shown in figure 1, point out that with university management in Lesotho, there is more of downward communication (71.2\%) than exchange of communication. Respondents, as shown in table 4, also point out the handicap of no feedback from management (80.8\%) after programmes or activities . respondents also noted that there is blockage of communication by middle management $(63 \%)$ and the result is fear of victimization by management.

\section{Conclusion}

Effective communication within institutions of higher learning contributes to quality delivery to the learner who is supposed to be the central beneficiary of the education system in any country. The theory informing this study is the hypodermic needle theory as the communication model of choice by some universities in Lesotho is the top to bottom model, with authorities predominantly talking down to subordinates with very little tolerance, consideration and accommodation of subordinate initiated communication. Effective communication is the remedy to effective and efficient management performance of employees in an organization. This study employed the quantitative technique and instruments for gathering and analyzing information.

\section{Recommendations}

The study recommends that the management of universities in Lesotho should be proactive in involving staff in communication processes in their institutions in order to make them feel valued. Communication should be timeous by making use of social media platforms that encourage free flow of ideas by all stakeholders in the institutions. Communications within these institutions should encourage transparency and build a sense of belonging and team work by all stakeholders so as to remove the fear of victimization and reluctance in participation in university activities and programmes.

\section{References}

[1] Asamu, F. F. (2014). The Impact of Communication on Workers' Performance in Selected Organizations in Lagos State, Nigeria. IOSR Journal of Humanities and Social Science (IOSR-JHSS) Volume 19, Issue 8, Ver.11 Aug. 2014) iosrjournals.org/iosr-jhss/papers/vol19issue8/version-2/K019827582.pdf

[2] Habaci, I., Celik, E. E., Habaci, M., Adiguzelli, F. \& Kurt, S. (2013) Effective Communication in Educational Administration. US- China Education Review B, ISSN 2161-6248 September 2013, Vol. 3.9,690-702 www.davidpublishing.com/davidpublishing/Upfile/9/ 26/.../2013092684838169.pdf

[3] Karten, N. (2002) Communication gaps and how to Close Them. www.dorsethouse.com/pdf/DorsetHouse-cgaps.pdf 
International Journal of Trend in Scientific Research and Development (IJTSRD) @ www.ijtsrd.com eISSN: 2456-6470

[4] Nebo, C. S., Nwankwo, P. N. \& Okonkwo, R. I. (2015) The Role of Effective Communication on Organizational Performance: A Study of Nnamdi Azikiwe University, Awka. Review of Public Administration and Management Vol.4, No. 8, December 2015. https://www.arabianjbmr.com/pdfs/RPAM_VOL_4_8/ 12.pdf

[5] Odiaka, E. C., Obinne, C. P. \& Folarin, A. B. (1999) Deviance in Organizational Communication: A Case from

Nigeria

https://www.researchgate.net/.../267365699_Devianc e_in_organizational_communicatio...

[6] Pillay,K. D. \& Hoque, M. (2015) Enhancing communication between management and employees at a storage organization in the freight ind ustry. Problems and Perspectives in Management, 13(2-1) businessperspectives.org/journals_free/ppm/2015/PPM _2015_02\%20cont_Pillay.pdf
[7] Proctor, C. (2014). Effective Organizational Communication Affects Employee Attitude, Happiness, and $\mathrm{Job}$ Satisfaction https://www.suu.edu/hss/comm/masters/capstone/t hesis/proctor-c.pdf

[8] Ronfeldt, M., Loeb, S. \&Wyckoff, J. (2012) How Teacher Turnover Harms Student Achievement. American Educational Research Journal $2013 \quad 50: 4$ https://aer.sagepub.com/content/50/1/4

[9] Singh, Y. (nd) Hypodermic Needle Theory/Mass MediaScribd

https://www.scribd.com/doc/533371001/Hypodermi c-Needle-Theory

[10] Turnbull, S. \& Schwartz, J. (2000) Models and Theories of Communication dalmasetto.com/pdfs/Comm_theory.pdf 